\title{
Pulsed nanocrystalline plasma electrolytic boriding as a novel method for corrosion protection of CP-Ti (Part 1: Different frequency and duty cycle)
}

\author{
M KH ALIEV and A SABOOR* \\ Faculty of Engineering, Materials Engineering Department, Tarbiat Modares University, P.O. Box 14115-143, \\ Tehran, Iran
}

MS received 3 May 2007; revised 26 July 2007

\begin{abstract}
Potentiodynamic polarization and electrochemical impedance spectroscopy were employed to test borided CP-Ti, treated by a relatively new method called pulsed plasma electrolytic boriding. The results show excellent corrosion resistance for modified CP-Ti. The effect of frequency and duty cycle of pulsed current was investigated. It was found that pulse frequency and duty cycle affect the size and porosity of nanocrystalline borides and by controlling these effective parameters, surface modification can render the CP-Ti material extremely corrosion resistant as a biomaterial.
\end{abstract}

Keywords. Titanium; pulsed plasma electrolytic boriding; corrosion; nanocrystalline.

\section{Introduction}

Titanium possesses low density, high strength-to-weight ratio, high stiffness and strength (Donachie 2000; Lutjering and Albrecht 2004). Commercially pure titanium (CP-Ti) is being investigated and recommended for elevated temperature applications where weight reduction is a prime concern. However, the resistance of CP-Ti to corrosion at room temperature has not been investigated and there are no reports of electrochemical studies to this end in service environments. Many studies have been published recently on the corrosion of CP-Ti (González and Mirza-Rosca 1999; Kuphasuk et al 2001; Burstein et al 2005; Shukla et al 2005). For implant applications, it is necessary to consider both biological and corrosion aspects. Other Ti-based alloys are also being investigated for implant applications. Also CP-Ti was evaluated as an implant material in some studies (Shukla et al 2005).

Some surface modification techniques have been developed for protection of titanium (Cai et al 2001; Vanzilotta et al 2006). Plasma electrolytic boriding (PEB) (Yerokhin et al 1999; Taheri et al 2007), as a new and effective surface treatment technique developed, has been used for surface modification of some alloys and some significant results have been reported. PEB process provides a titanium having thick, hard, high corrosion resistant ceramiclike nitride and carbide films composed of a porous nanocrystalline layer.

\footnotetext{
*Author for correspondence (sabour02@yahoo.com)
}

In this particular work, the corrosion behaviour of CP-Ti in Ringer's solution, used to simulate human body fluids, is investigated for borided samples at different conditions. Two electrochemical techniques were used for this purpose: potentiodynamic polarization and electrochemical impedance spectroscopy (EIS). Standard corrosion parameters such as corrosion current density $\left(i_{\text {corr }}\right)$, corrosion potential $\left(E_{\text {corr }}\right)$, polarization resistance $\left(R_{\mathrm{p}}\right)$ and corrosion rate $\left(C_{\mathrm{R}}\right)$ were calculated from these experiments.

The effect of coating parameters on the properties of PEB films on CP-Ti have not been well studied and the relationship between electronic characteristics and corrosion properties of PEB film is also seldom studied. In this investigation, effects of two different effective parameters (frequency and duty cycle of pulse current) in borax base electrolyte on the structure, composition and corrosion resistance of commercially pure titanium (CPTi) with PEB film were studied. Based on the results, corrosion resistance of the PEB films was analysed.

\section{Materials and methods}

CP-Ti was received in the form of a rod having a diameter of $25 \mathrm{~mm}$. Disc-shaped specimens with thickness, $5 \mathrm{~mm}$ and diameter, $20 \mathrm{~mm}$ were obtained from the centre of these rods using usual machining. Prior to surface treatment, each specimen was ground with $240-3000$ grit $\mathrm{SiC}$ paper and ultrasonically cleaned with alcohol. The corrosion measurements for each experimental condition were carried out using a potentiostat/galvanostat (EG\&G 273A, 
Princeton Applied Research), a standard cell and electrode holders. SCE was used as the reference electrode and the counter electrode consisted of platinum plate. The surface area exposed to the electrolyte was $0.785 \mathrm{~cm}^{2}$. The corrosion behaviour of the treated CP-Ti was evaluated at room temperature using Ringer's solution which was not deaerated, with an approximate $\mathrm{pH}$ between 5 and 6.

The potentiodynamic polarization curves for the samples were recorded for a potential scan from $-0.4 \mathrm{~V}$ vs open circuit potential to $1.5 \mathrm{~V}$ vs saturated calomel electrode at a scan rate of $0.5 \mathrm{mV} / \mathrm{S}$. The polarization curves were analysed to determine $E_{\text {corr }}$ (corrosion potential) and $i_{\text {corr }}$ (corrosion current). The corrosion rate, $C_{\mathrm{R}}$ (rate of metal dissolution), in millimeters per year, was determined with the following standard equation

$$
C_{\mathrm{R}}=\left(i_{\text {corr }} \times A_{\mathrm{W}}\right)(z \times F \times \rho)^{-1},
$$

where $A_{\mathrm{W}}, z$ and $\rho$ are characteristic properties of each sample (atomic weight, valence and density, respectively) and $F$ the Faraday constant $(96500 \mathrm{As} / \mathrm{mol})$. Equivalent weights based on standard equations were obtained to calculate the corrosion rate.

Electrochemical impedance spectroscopy was also used to evaluate the samples. This method was conducted according to the ASTM G-106 standard practice. Samples were left in contact with Ringer's solution at open circuit conditions for $1 \mathrm{~h}$ prior to carrying out the EIS tests. The a.c. impedance spectra for $\mathrm{CP}-\mathrm{Ti}$ were obtained at the open circuit potential, with a scan frequency range of $100 \mathrm{kHz}-$ $10 \mathrm{mHz}$ with an amplitude of $10 \mathrm{mV}$ to obtain 30 experimental points. Nyquist plots were obtained by curve fitting these data points using a commercial software package called 'Electrochemistry Power Suite'. These plots were analysed to determine the solution resistance $\left(R_{\Omega}\right)$, polarization resistance at the electrode/solution interface $\left(R_{\mathrm{p}}\right)$, and the double layer capacitance at this interface $\left(C_{\mathrm{DL}}\right)$. Bode plots were also plotted from the same data to better analyse and understand the corrosion phenomena occurring during the impedance tests.

CP-Ti samples used in this study were modified by different conditions of pulsed plasma electrolytic boriding. All these samples were borided at $600 \mathrm{~V}$ by rectangular pulse shape method at different frequencies and duty cycles. Electrolyte bath which was made from stainless steel acted as anode in electrochemical system of coating process. Other specifications can be found elsewhere (Aliofkhazraei et al 2005; Taheri et al 2007). The borided layer formed as a result of the plasma electrolysis process had a thickness of about $10 \mu \mathrm{m}$ for all samples. The as-received samples were used as control for comparison purposes. All corrosion testing was carried out at $25^{\circ} \mathrm{C}$. Four samples were tested for each experimental condition and the average of these results is reported. Earlier data was not included in these calculations.

\section{Results and discussion}

Micrographs of samples were obtained by electron backscattering using scanning electron microscope (SEM) (Philips XL-30 and CamScan MV-2300).

The modified surfaces were observed in SEM by mounting the samples in a polymeric resin. Figure 1 is an example of two different samples with different duty cycles and shows the difference between the sizes of nanocrystalline borides. It seems that increasing the frequency of coating process will produce structures like nanorods and decreasing it will lead to spherical nanocrystals.

\subsection{Corrosion experiments}

Standard techniques were used to extract $E_{\text {corr }}, i_{\text {corr }}$ and $C_{\mathrm{R}}$ values from the potentiodynamic polarization plots, samples of which are shown in figures 2 and 3. Table 1 shows the polarization data obtained for CP-Ti including Tafel slopes $\left(\beta_{\mathrm{a}}\right.$ and $\left.\beta_{\mathrm{c}}\right), E_{\text {corr }}$ and $i_{\text {corr }}$ values.

From this table it is possible to observe low values of corrosion rate for all the samples. The formation of boride films on the CP-Ti samples resulting from surface treatment renders these samples passive and highly corrosion resistant in Ringer's solution.

Data from EIS was obtained as Nyquist plots and analysed to determine the solution resistance $\left(R_{\Omega}\right)$, polarization resistance at the electrode/solution interface $\left(R_{\mathrm{p}}\right)$, and a double layer capacitance at this interface $\left(C_{\mathrm{DL}}\right)$. Among
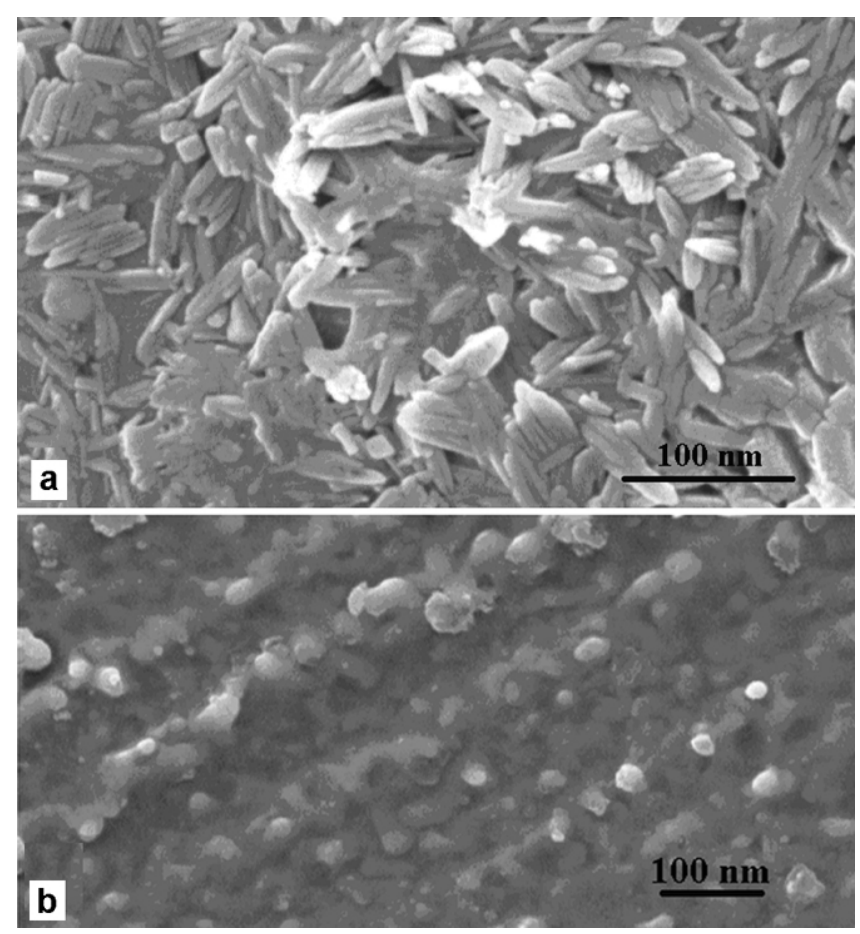

Figure 1. Nanocrystalline borides on the compound layer of sample a. $1000 \mathrm{~Hz}, 20 \%$ and b. $10 \mathrm{~Hz}, 20 \%$. 
Table 1. Corrosion parameters from potentiodynamic polarization tests.

\begin{tabular}{lccccr}
\hline $\begin{array}{l}\text { Frequency, } \\
\text { duty cycle }\end{array}$ & $\beta_{\mathrm{a}}(\mathrm{mV} /$ decade $)$ & $\beta_{\mathrm{c}}(\mathrm{mV} /$ decade $)$ & $E_{\text {corr }}(\mathrm{mV} / \mathrm{SCE})$ & $i_{\text {corr }}\left(\mu \mathrm{A} / \mathrm{cm}^{2}\right)$ & $C_{\mathrm{R}}(\mathrm{mm} / \mathrm{y})$ \\
\hline $10 \mathrm{~Hz}, 20 \%$ & 364.72 & 201.44 & -343 & $0 \cdot 64$ & $9 \cdot 68 \times 10^{-3}$ \\
$100 \mathrm{~Hz}, 20 \%$ & 371.02 & 216.72 & -320 & 0.28 & $4.24 \times 10^{-3}$ \\
$1000 \mathrm{~Hz}, 20 \%$ & 370.81 & 340.27 & -194 & $0 \cdot 16$ & $2.44 \times 10^{-3}$ \\
$1000 \mathrm{~Hz}, 50 \%$ & 359.83 & 150.08 & -337 & $0 \cdot 2$ & $3 \times 10^{-3}$ \\
$1000 \mathrm{~Hz}, 10 \%$ & 374.5 & 172.31 & -219 & $0 \cdot 1$ & $1.6 \times 10^{-3}$ \\
$\mathrm{CP}-\mathrm{Ti}$ & 351.2 & 269.05 & -387 & 0.68 & $10 \cdot 3 \times 10^{-3}$ \\
\hline
\end{tabular}

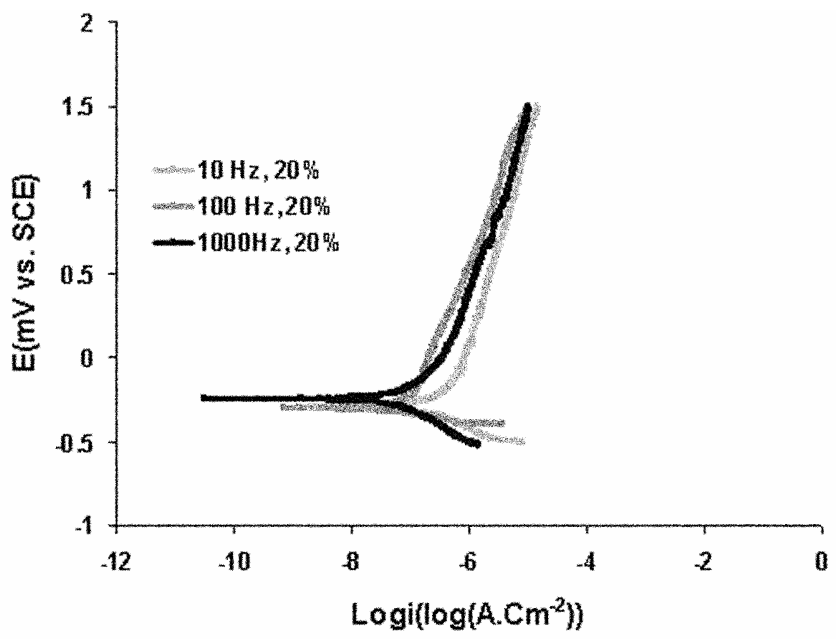

Figure 2. Polarization curves of samples treated at different frequencies.

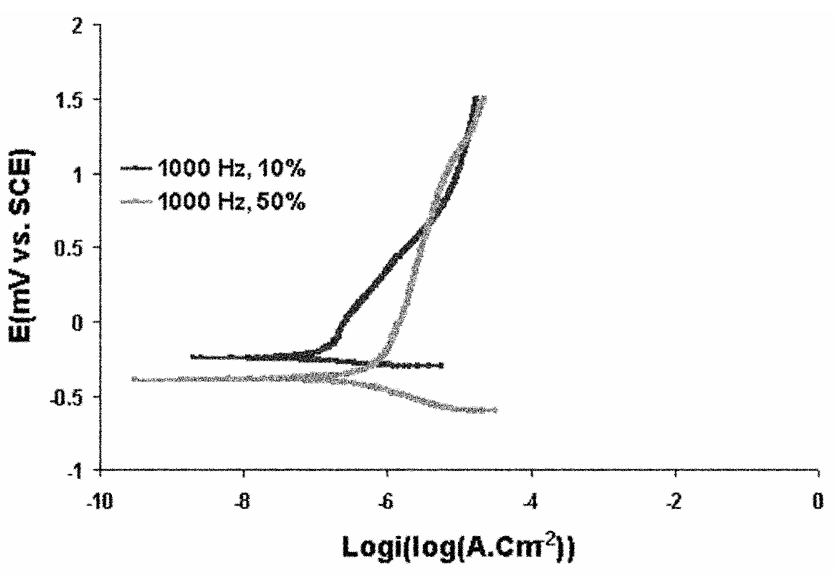

Figure 3. Polarization curves of samples treated at different duty cycles.

these parameters, $R_{\mathrm{p}}$ is the factor that determines corrosion resistance of samples. This value is inversely proportional to $i_{\text {corr }}$, and hence, high values of $R_{\mathrm{p}}$ correspond to low corrosion rates. This technique was used to compare the results obtained from potentiodynamic polarization tests. Figures 4 and 5 show Nyquist plots obtained experimentally for CP-Ti in Ringer's solution, respectively. The impedance spectra shown in figure 4 for CP-Ti indicate that the best corrosion resistance was exhibited for samples borided at high frequencies in comparison with other samples. This behaviour can be attributed to the presence of a denser compound layer formed with this treatment by higher frequencies. On the other hand, for samples borided at lower frequencies, the corrosion resistance was lower, possibly due to the presence of more porous complex boride layer, which is not expected to provide significant corrosion resistance for these samples. The Nyquist plots obtained for CP-Ti at different duty cycles (figure 5) indicate that the best corrosion resistance is obtained for the borided samples at lower duty cycles in comparison with the samples obtained by higher duty cycles, and this can be attributed to the presence of a well performed and lower sizes of nanocrystalline borides in compound layer on the CP-Ti surface and corroborated by the polarization data in table 1 . Although attempts were made with X-ray diffraction to determine the nature of the boride layer formed on CP-Ti during the plasma electrolytic process, this layer has not been clearly identified as yet.

Table 2 shows the corrosion parameters obtained for CP-Ti with EIS. This table shows the values of solution resistance $\left(R_{\Omega}\right)$, polarization resistance $\left(R_{\mathrm{p}}\right)$ and capacitance of the double layer $\left(C_{\mathrm{DL}}\right)$ obtained by curve fitting the EIS data using the 'Electrochemistry Power Suite'. Consistent values of electrolyte resistance $\left(R_{\Omega}\right)$ are noted for CP-Ti in Ringer's solution.

The higher value of $R_{\Omega}$ in the case of CP-Ti sample borided at lower frequencies is possibly a manifestation of the porous complex titanium borided layer. Large values of polarization resistance $\left(R_{\mathrm{p}}\right)$ are also noted in all the samples. A high $R_{\mathrm{p}}$ value is an indication of the working electrode strongly resisting change from its equilibrium state and corresponds to a low rate of titanium ion release. This behaviour is clearly noted and is in agreement with the results found with potentiodynamic polarization. From table 2 it can also be seen that, in general, for all surface treatments in Ringer's solution, high values of polarization resistance $\left(R_{\mathrm{p}}\right)$ ranging from $107-513 \mathrm{M} \Omega \mathrm{cm}^{2}$ are measured, which implies an excellent corrosion resistance for this metal after surface modification. Also values of $C_{\mathrm{DL}}$ in the range $30-40 \mu \mathrm{F} \cdot \mathrm{cm}^{-2}$ were determined. The $R_{\text {coat }}$ values for the two samples treated at different 
Table 2. A.C. impedance parameters for CP-Ti samples.

\begin{tabular}{lccccc}
\hline $\begin{array}{l}\text { Frequency, } \\
\text { duty cycle }\end{array}$ & $R_{\Omega}\left(\Omega \cdot \mathrm{cm}^{2}\right)$ & $R_{\mathrm{p}}\left(\mathrm{M} \Omega \cdot \mathrm{cm}^{2}\right)$ & $C_{\mathrm{DL}}\left(\mu \mathrm{F} \cdot \mathrm{cm}^{-2}\right)$ & $R_{\text {coat }}\left(\mathrm{K} \Omega \cdot \mathrm{cm}^{2}\right)$ & $\mathrm{CPE}_{\mathrm{coat}}\left(\mu \mathrm{F} \cdot \mathrm{cm}^{-2}\right)$ \\
\hline $10 \mathrm{~Hz}, 20 \%$ & $8 \cdot 24$ & $107 \cdot 78$ & $31 \cdot 1$ & $824 \cdot 74$ & $3 \cdot 2$ \\
$100 \mathrm{~Hz}, 20 \%$ & $7 \cdot 33$ & $212 \cdot 16$ & $34 \cdot 9$ & $1463 \cdot 9$ & $6 \cdot 4$ \\
$1000 \mathrm{~Hz}, 20 \%$ & $7 \cdot 28$ & $481 \cdot 55$ & $31 \cdot 4$ & $2151 \cdot 5$ & $3 \cdot 6$ \\
$1000 \mathrm{~Hz}, 50 \%$ & $7 \cdot 39$ & $229 \cdot 93$ & 30 & $1322 \cdot 4$ & $3 \cdot 5$ \\
$1000 \mathrm{~Hz}, 10 \%$ & $5 \cdot 5$ & $512 \cdot 43$ & $39 \cdot 3$ & $2484 \cdot 9$ & $1 \cdot 3$ \\
CP-Ti & $9 \cdot 82$ & $97 \cdot 28$ & $17 \cdot 6$ & - & - \\
\hline
\end{tabular}

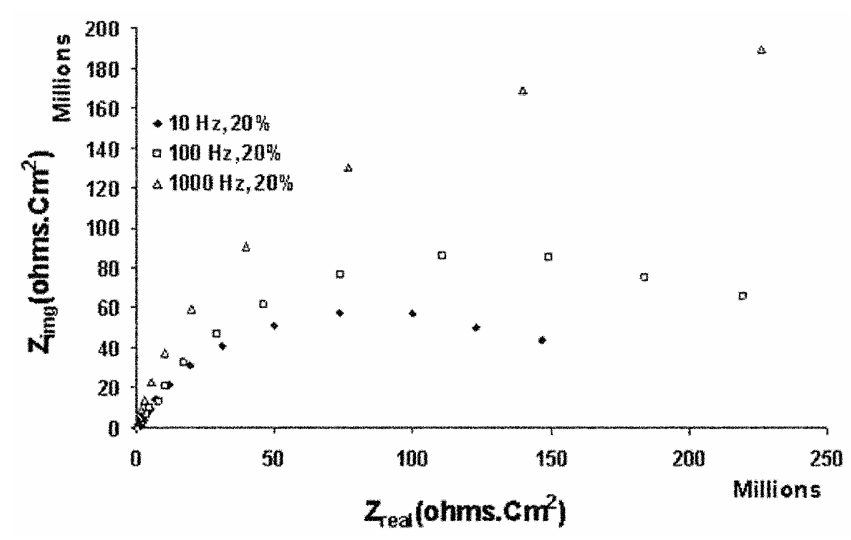

Figure 4. Nyquist plots for samples treated at different frequencies.

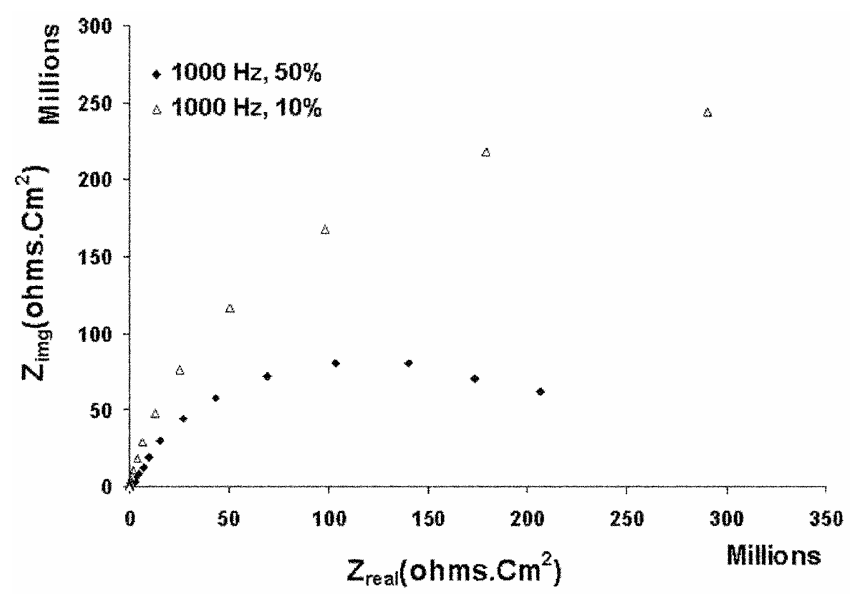

Figure 5. Nyquist plots for samples treated at different duty cycles.

opposite duty cycles and frequencies $(1000 \mathrm{~Hz}, 10 \% ; 10 \mathrm{~Hz}$, $20 \%)$ reveal an interesting point. First sample $(1000 \mathrm{~Hz}$, $10 \%$ ) has a lower value of $\mathrm{CPE}_{\text {coat }}$ and its $R_{\text {coat }}$ value formed during EIS tests is larger than the other sample $(10 \mathrm{~Hz}, 20 \%)$ treated at a duty cycle of $10 \%$. This reflects the presence of a relatively coherent and stable boride layer formed on first sample $(1000 \mathrm{~Hz}, 10 \%)$ with this treatment, while the obtained layer formed on other sample $(10 \mathrm{~Hz}, 20 \%)$ is porous and possibly less stable. During impedance testing, this porous boride is made denser by passivation, reflected in a larger value of $\mathrm{CPE}_{\text {coat }}$. Bode phase plot spectra from the EIS data were evaluated to observe changes in the sample surface during EIS testing. From this graph it is possible to deduce the presence of a compact film, if (a) the phase angle is close to $90^{\circ}$ over a wide frequency range, and (b) if the spectrum shows linear portions at intermediate frequencies. Figure 6 shows representative Bode plots for two samples treated at opposite frequencies and duty cycles $(10 \mathrm{kHz}, 10 \% ; 10 \mathrm{~Hz}$, $60 \%$ ) in Ringer's solution as examples. The impedance spectra found for the sample $(10 \mathrm{kHz}, 10 \%)$ exhibited a near capacitive response illustrated by a phase angle close to $85^{\circ}$, while the sample $(10 \mathrm{~Hz}, 60 \%)$ showed a phase angle close to $80^{\circ}$ over a wide frequency range. This response and the high values of $R_{\mathrm{p}}$ obtained from the $\mathrm{Ny}$ quist plot corroborates the presence of a barrier layer formed on this metal after surface treatment especially for sample $(10 \mathrm{kHz}, 10 \%)$. Sample $(10 \mathrm{kHz}, 10 \%)$ has the highest frequency and lowest duty cycle in this study which tends to receive the lowest size of nanocrystalline borides on its surface. It seems that compact layer with nanocrystalline borides with smaller dimensions shows a better corrosion behaviour. This fact is obviously clear for all samples treated in this study. So by increasing frequency and decreasing duty cycle of the pulse current, the corrosion behaviour of the samples will improve significantly.

In all the cases, a simple EEC model shown in figure 7 is sufficient to explain the observed EIS data. No attempt was made to compare simulations of this EEC model with the data already obtained, since the model itself was suggested by the commercial software used.

The corrosion behaviour of borided CP-Ti in Ringer's solution was experimentally studied and it appears that this material has excellent corrosion resistance based on both direct current and a.c. techniques.

Although the main aim of this study was to investigate the resistance to corrosion of CP-Ti in a physiological environment, a number of points regarding the type and composition of boride formed after plasma electrolysis and the oxide film growth in Ringer's solution for the samples $(10 \mathrm{kHz}, 10 \%, 10 \mathrm{~Hz}, 60 \%)$ (different opposite frequencies and duty cycles) need to be further elaborated. Also, parametric studies for optimization of the protective boride film and subsequent wear tests should be carried out. 


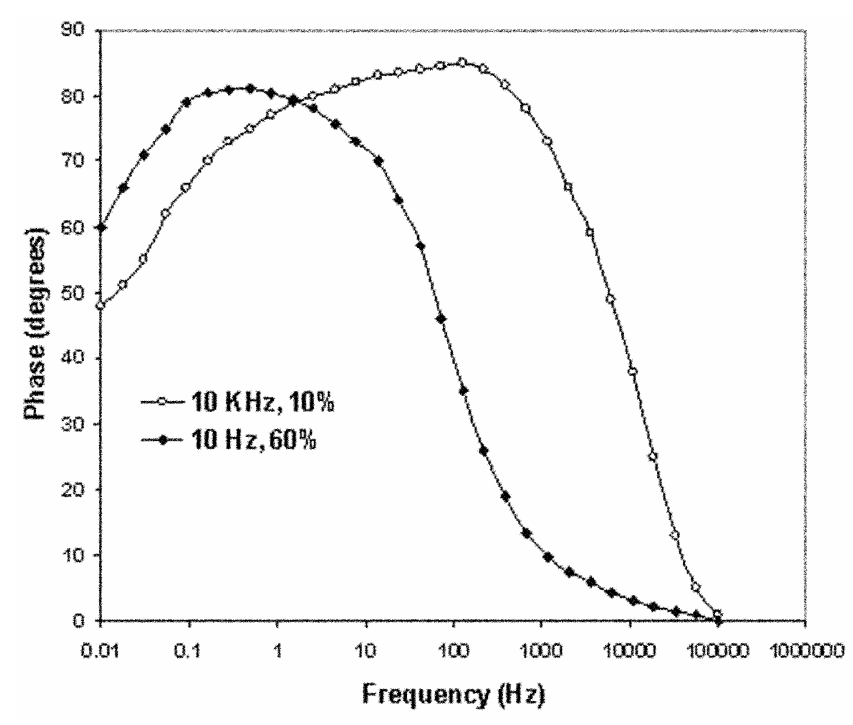

Figure 6. Bode phase plots for samples $(10 \mathrm{kHz}, 10 \% ; 10 \mathrm{~Hz}$, $60 \%$ ) in Ringer's solution.

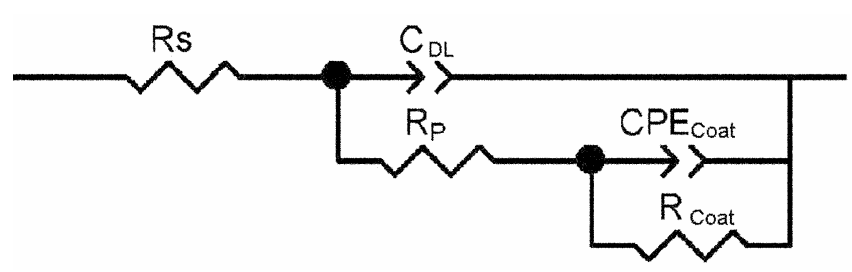

Figure 7. Equivalent electrical circuit for all borided samples.

\section{Conclusions}

The kinetic parameters $\left(E_{\text {corr }}, i_{\text {corr }}\right)$ obtained by the potentiodynamic polarization technique indicate excellent corrosion resistance for pulsed plasma electrolytic borided CP-Ti. Both electrochemical techniques show that these samples exhibit a corrosion behaviour in Ringer's solution better than raw CP-Ti and by increasing frequency and decreasing duty cycle of pulse current, not only the size of nanocrystalline borides will decrease, but also the corrosion characteristics will improve significantly. Surface boriding at $1000 \mathrm{~Hz}$ significantly increases the corrosion resistance of $\mathrm{CP}-\mathrm{Ti}$, while boriding at $10 \mathrm{~Hz}$ results in the formation of a porous borided layer. In general, the low values of corrosion rate, and high values of polarization resistance $\left(R_{\mathrm{p}}\right)$ obtained experimentally for borided CP-Ti in Ringer's solution, imply that this material has the potential to be considered as a biomaterial.

\section{Acknowledgements}

The authors would like to express their gratitude to the National Association of Nanoscience and Nanotechnology of Iran and Arvandan Oil and Gas Company (TMU 8509-66) for financial support.

\section{References}

Aliofkhazraei M et al 2005 Iran Pat. No. 35550

Burstein G T, Liu C and Souto R M 2005 Biomaterials 26 245

Cai Z, Bunce N, Nunn M E and Okabe T 2001 Biomaterials 22 979

Donachie M J 2000 Titanium a technical guide (USA: ASM International) 2nd edn

González JE G and Mirza-Rosca J C 1999 J. Electroanal. Chem. 471109

Kuphasuk C, Oshida Y, Andres C J, Hovijitra S T, Barco M T and Brown D T 2001 J. Prosthet. Dent. 85195

Lutjering G and Albrecht J 2004 Ti-2003 Science and Technology (Germany: Wiley-VCH)

Shukla A K, Balasubramaniam R and Bhargava S 2005 Intermetallics 13631

Taheri P, Dehghanian Ch, Aliofkhazraei M and Sabour A R 2007 Plasma Processes and Polym. 44

Vanzillotta P S, Sader M S, Bastos I N and de Almeida Soares G 2006 Dental Mater. 22275

Yerokhin A L, Nie X, Leyland A, Matthews A and Dowey S J 1999 Surf. Coat. Technol. 12273 